\title{
MITOS, SEXUALIDADE E REPRESSÃO (1)
}

\author{
Paulo Roberto Ceccarelli
}

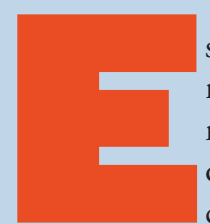

ste texto dá continuidade a uma pesquisa que venho realizando há alguns anos a respeito das relaçóes entre mitologia, sexualidade e repressão (2) (3). A hipótese que desenvolvo neste trabalho pode ser assim enunciada: ainda que o recalque (Verdrängung) da sexualidade seja o movimento universal que marca o modo de circulação pulsional própria do humano, sendo a condição primeira para a existência do estado de cultura (4), a repressão (Unterdrückung) da sexualidade que se seguirá geradora da moral sexual é tributária do sistema de valores que sustenta o imaginário social. As origens deste sistema devem ser procuradas nos mitos fundadores da cultura em questão. E o lugar da sexualidade nos relatos mitológicos - pecado, culpa, responsável pela queda, fonte de prazer... - marcará profundamente as formações ideais e superegoicas responsáveis pelo modo como o sujeito vivencia, consciente e inconscientemente, sua sexualidade. Os princípios estipulados pela moral sexual introduzem no Eu em formação, via identificação, regras de conduta que, muitas vezes, estão em completa oposição aos destinos pulsionais. Ainda que alguns sujeitos não se deixem influenciar pelos mitos de origem, eles não são imunes às suas influências devido à introjeção dos ideais sociais. É, também, dos mitos de origem que os discursos, ideológico e político, tiram a sua força ao apresentá-los como verdades universais e/ou como revelaçôes divinas a serem seguidas sem questionamentos.

Uma outra hipótese que desenvolvo é que certas manifestações da sexualidade, definidas pelo referencial psicanalítico como perversas, podem ser entendidas como subprodutos da cultura ocidental. Dito de outra forma: as perversões seriam o retorno, sob o modo perverso, do reprimido. Lembro mais uma vez: do reprimido e não do recalcado. O retorno do recalcado gera o sintoma neurótico.

A moral sexual é um fato da cultura. Toda sociedade possui regras a respeito do uso da libido. A leitura de inúmeros textos, sobretudo os antropológicos, sugerem que um certo controle em relação ao prazeres da carne tem sido, em intensidades diferentes e em momentos sócio-históricos variáveis, um elemento constitutivo do humano. Da antiguidade até nossos dias, a regulamentação dos prazeres tem recebido tratamentos diferentes.

As teses freudianas apresentadas no texto Moral sexual "ivilizada" e doença nervosa moderna sugerem que a maneira da cultura ocidental lidar com a sexualidade guarda profundas relaçôes com a forma com que os mitos de origem tratam a sexualidade. $\mathrm{O}$ preço a pagar pela "evolução" é o controle da sexualidade. "Cada nova conquista foi sancionada pela religião, cada renúncia do indivíduo à satisfação pulsional foi oferecida à divindade como um sacrifício" (5). Nesse texto, Freud discute não apenas as doenças nervosas dos tempos modernos, devido às limitações impostas à sexualidade pela moral sexual civilizada, mas 
também propõe soluções que são um verdadeiro projeto político, na medida em que dizem respeito à saúde da população em geral. Freud defende que uma reforma social permitiria mais liberdade sexual, pois neutralizaria os traumatismos advindos da repressão. A conclusão final de Freud sobre a condição humana é um choque frontal com o livre arbítrio agostiniano: Aqueles que desejam ser mais nobres do que suas constituições lhes permitem, são vitimados pela neurose (6). Lembremo-nos que Freud fala de repressão (Unterdrückung) e não de recalque (Verdrängung): "a influência prejudicial da civilização reduzse principalmente à repressão nociva (die Schädlich Unterdrückung) da vida sexual dos povos (ou classes) civilizados através da moral sexual 'civilizada' que os rege" (7).

QUAIS AS FUNÇÕES DOS MITOS? Os mitos, cujas origens se confundem com a dos homens, representam o capital fantasmático de uma cultura. Graças à cosmogonia que sustentam, cria-se um ponto de partida que permite fundar historicamente a origem do homem, dos animais e das coisas, assegurando a passagem do caos à ordem, do irrepresentável às representaçôes linguísticas, do gozo ao desejo. Os relatos míticos balizam o caminho, sempre imaginário, através da barra do recalque ligando o processo primário ao secundário.

O comum entre o capital fantasmático dos diferentes grupos humanos não é o que é dito, mas o que é visado: dar sentido às questôes que os humanos desde sempre tiveram que afrontar. $\mathrm{Ou}$ seja, o fato de nascer, de viver, de morrer, de como enfrentar o poder e a violência da natureza, a violência dos outros e a própria: "este é o ponto comum a todas as culturas: as interrogaçóes existenciais que ultrapassam as diferenças" (8).

Nesta perspectiva, pode-se dizer que do ponto de vista da economia libidinal, os mitos têm o mesmo estatuto que o da realidade psíquica: são relatos que oferecem representaçôes às pulsões. Da mesma forma que a cartografia mitológica construída no processo psicanalítico permite ao sujeito resignificar a sua história e atribuir representações a seus afetos, os mitos fundadores de uma cultura fornecem os elementos que dão sentido tanto ao mundo visível quanto ao fantasmático. Além disso, os mitos cumprem uma importante função ideológica: a de apresentar a ordem simbólica, que sustenta a social, como sagrada, universal e imutável, ao invés de uma construção sócio-histórica arbitrária, logo, mutável (9).

Resumindo: o mito fundador está para a cultura assim como o mito individual está para o sujeito: uma palavra fundadora de identidade. Sua perda pode ser experimentada tanto pelo sujeito quanto pela cultura com uma perda das referências identificatórias, pois ela desfaz a circulação pulsional, provocando o colapso da função imaginária e simbólica, fazendo emergir o real produtor de estados de angústia que podem chegar aos chamados "ataque de pânico", à desorganização psíquica ou, nos casos mais drásticos, a episódios psicóticos.

Posto que "a psicologia individual (...) é, ao mesmo tempo, também psicologia social” (10), penso que em todo mito individual existe a participação do mito coletivo. E é na constituição das instâncias ideais e superegoicas que se entrelaçam os mitos coletivos e os individuais: o ideal do Eu é marcado pelos ideais coletivos.
Os ideais da nossa cultura, assim como as bases do discurso que define nossa visão de mundo, encontram suas origens no imaginário da cultura ocidental, cujas fontes remontam aos mitos fundadores descritos na Bíblia. Tais mitos participam intensamente na nossa concepção do bem e do mal, do verdadeiro e do falso, do pecado, determinam as relações sexuais aceitas e as proibidas, ditam as posiçôes sociais dos homens e das mulheres, as relações de trabalho, dentre outras coisas. Ou seja, os ideais sustentam a ideologia e justificam o discurso do poder. As associações sintagmáticas que utilizamos para decodificar o mundo são impregnadas pelos valores ditados por esse discurso que é tomado como universal. Uma das consequências, às vezes catastrófica, de tal posição é o risco que, frente à outra forma de apreender o mundo, reagiríamos de maneira normativa, ou mesmo carregada de preconceitos, pois nossas certezas são ameaçadas (11).

A REPRESSÃO SEXUAL EM OUTRAS CULTURAS Voltemos à questão central do texto: a participação dos mitos de origem nos destinos da repressão sexual. A repressão sexual que se segue ao recalque, já o dissemos, é tributária do sistema de valores que sustenta o imaginário social que, por sua vez, guarda estreita ressonância com os mitos de origem da sociedade em questão. Nessa perspectiva, é lícito supor que "a vida sexual" de uma sociedade - ou seja, as práticas sexuais às quais os seus membros se entregam, com os aspectos conscientes e inconscientes, com suas possibilidades, limites e proibições - será fortemente determinada pelo lugar atribuído à sexualidade nos mitos de origem. Na cultura ocidental, os mitos fundadores apresentam a sexualidade, sobretudo, a partir da "sexualização" do pecado original feita por Santo Agostinho, como a responsável pela perda do paraíso, com todos os desdobramentos que se seguem, em particular, o lugar atribuído às mulheres.

Pois bem, o que acontece nas culturas nas quais os mitos de origem não apresentam a sexualidade como um problema, e muito menos como um pecado ou, ainda, quando ela é apresentada como fonte de prazer (12)? Encontraríamos ali as mesmas manifestaçōes ditas perversas da sexualidade?

Os importantes estudos de antropologia e psicanálise feitos por Georges Devereux e Géza Róheim mostram a participação da cultura na estruturação do sistema regulador das pulsões $(13 ; 14)$. De forma resumida, podemos dizer que as observações desses autores confirmam a universalidade do polimorfismo sexual infantil. Ao mesmo tempo, eles observam que as diferentes apresentações desse polimorfismo devem-se às particularidades culturais. Ou seja, o que diferencia as expressões da sexualidade são "fatores de ordem cultural” (13). Para Róheim (14), que interpreta a história como um infindável conflito entre Eros e Tánatos, a utilização da psicanálise em outras culturas só pode ser feita quando apoiamos o universal da psicanálise, nas particularidades do sistema social e nas instituições de base da cultura em questão.

No entanto, nem Devereux e nem Róheim interessaram-se, assim me parece, em compreender as bases mitológicas que determinam a particularidade de cada uma das culturas estudadas. Além disso, nessas culturas a sexualidade genital não é, como na cultura ocidental, um assunto de ordem divina. 
Isto não quer dizer, é sempre bom lembrar, que a sexualidade nas culturas estudadas por esses pesquisadores seja sem constrangimentos e que esses povos vivam de forma libertina, o que corresponderia ao mito do "selvagem feliz", que uma certa leitura de Bronislaw Malinowski (15) deixaria pensar. No entanto, quando lemos este último, apesar das críticas que podem ser feitas a essa obra pioneira, chama-nos a atenção o fato que, embora as questões centrais da psicanálise estejam presentes, a relação entre os mitos de origem e a sexualidade não é central nessa cultura. Ao contrário: ainda que a sexualidade, sobretudo, na sua vertente incestuosa, assim como o canibalismo, não esteja ausente da mitologia dessa cultura, ela não é a responsável por qualquer forma de punição participando, além disso, de forma positiva nos mitos fundadores. Ademais, é interessante constatar que nas observações de Malinowski sobre os habitantes das Ilhas Trobriands não existem relatos de comportamentos sexuais que poderiam ser classificados de perversões.

O mesmo observamos a partir da leitura de alguns mitos indígenas da Amazônia. Não é nossa intenção abordar de maneira exaustiva e sistemática os relatos mitológicos desses povos, e as conclusôes às quais chegamos não podem evidentemente ser generalizadas. Posto isso, nas obras consultadas $(12 ; 16 ; 17 ; 18 ; 19 ; 20 ; 2$ $1 ; 22 ; 23 ; 24)$, a sexualidade não aparece nos mitos de origem como algo "negativo". Embora tabus e proibições encontrem-se presentes, às vezes, de forma bem mais rígida que na sociedade ocidental. O que está em jogo, nesse caso, é o recalque da sexualidade. No que diz respeito à repressão, esta não traz a marca do pecado e da transgressão, a serem punidos de forma terrível através das gerações: o pecado original.

Prosseguindo a minha reflexão, pergunto: as perversões estão presentes em todas as culturas? A discussão sobre as organizaçōes perversas da sexualidade em si só mereceriam todo um capítulo. Para os propósitos deste texto, limitarme-ei às perversões descritas por Freud nos Três ensaios em que ele as define como uma "fixação da libido", e o subsequente retorno aos pontos de fixação. Trata-se de um desenvolvimento exagerado de uma pulsão parcial: ao invés de encontrar satisfação em um prazer preliminar como pulsão componente, ela escapa à primazia genital tornando-se a principal forma de satisfação. Ora, embora a dinâmica pulsional responsável para a fixação da libido em uma forma de prazer deva ser entendida na particularidade de cada caso, podemos supor que a repressão da sexualidade participe nesse processo.

Se, como diz Freud (25) em $O$ mal-estar na cultura, o destino do indivíduo não pode ser estudado fora da comunidade na qual ele se insere, acredito que algumas formas de perversōes sejam consequência de como a repressão sexual atua na cultura ocidental. Isto é: quanto mais repressora for a sociedade em relação às manifestações da sexualidade, mais ela produz pontos de fixação da pulsão. Por exemplo, quando uma criança, durante o processo de descoberta e erotização do corpo próprio, é informada de que certas partes desse corpo não podem ser tocadas e, às vezes, nem mesmo nomeadas, o risco de fixação da libido é grande. A maneira como alguns adultos tradu- zem as brincadeiras infantis, devido a problemas com a sua própria sexualidade, pode criar pontos de fixação da libido. É assim que, do ponto de vista da dinâmica pulsional, a pedofilia pode ser entendida como duas "crianças" em plena brincadeira infantil. O que transforma essa prática sexual em perversão é que um dos protagonistas da cena impõe à criança algo que não faz parte de seu universo fantasmático naquele momento, o que pode levar a um excesso pulsional que provoca no Eu em desenvolvimento um transbordamento de excitação com o qual a criança não tem condições de lidar. O mesmo vale para as formas de "educação" que visam alertar os jovens contra possíveis assédios sexuais: o verdadeiro assédio pode estar na forma de conduzir a questão, no sentido discutido por Sandór Ferenczi (26) em seu texto Confusão de línguas entre o adulto e a criança.

Max Weber, em seu trabalho de referência, intitulado Ética protestante o espírito do capitalismo, nos dá algumas pistas que confortam a nossa hipótese. Segundo ele, a repressão da sexualidade é necessária para a produção capitalista: "contra todas as tentaçôes sexuais, da mesma forma que contra as dúvidas religiosas ou o sentimento de indignidade moral, além de uma alimentação frugal e a supressão de carne e banhos frios, temos ainda o preceito: 'trabalhe com afinco para as suas necessidades"” (27). Em termos psicanalíticos: reprima a sexualidade para que ela seja reutilizada, via sublimação, para a produção capitalista. Para Weber, a interpretação racional da vida sexual teria gerado uma forma de refinamento, e uma impregnação espiritual e ética nas relações do casal, levando ao surgimento de um cavalheirismo conjugal. Acredito que o cavalheirismo conjugal não poderia acontecer sem um rígido controle da sexualidade via repressão. As correntes libidinais reprimidas fazem retorno expressando-se em soluçōes perversas da sexualidade (28).

É assim que procuro entender, como tive a oportunidade de discutir em um trabalho anterior (29), a que ponto a moral sexual civilizada continua em pleno vigor nas inúmeras versões do "politicamente correto", que transforma atos banais em assédio sexual.

CONCLUSÃO Quando os mitos de origem separam "bem" e "mal" de forma clara, a formulação do conceito do normal e do patológico será mais rígida, e os desvios perversos mais frequentes. A dicotomia radical entre "bem" e "mal", que reflete a efração de Eros e Tânatos, é retratada de forma exemplar nas posições fundamentalistas: nós somos o bem e eles o mal (demoníacos); o bem deve levantar-se contra o "eixo do mal". As tentativas de fixar as pulsões em formas ideologicamente predeterminadas de satisfação servem a Tânatos, na medida em que uma pretensa ligação completa em nome da pulsão de vida, leva à morte, pois nenhum espaço é deixado para a circulação pulsional (30). A maior ou menor rigidez do sistema de valores de uma dada sociedade é tributária da rigidez pulsional da mitologia de origem desta sociedade. Uma sociedade na qual os deuses são mais "humanos" é menos repressora do que aquela que cobra de seus membros um altíssimo preço por terem sido criados "à imagem e semelhança de Deus". 
Embora não haja como escapar de uma mitologia que nos informe sobre nossas origens, não podemos nos esquecer que estamos lidando com um relato imaginário que nos permite falar do antes; falar dos elementos a partir dos quais a ordem simbólica se organizou sem que, no entanto, exista uma forma única de organização desta ordem: tratar um determinado arranjo simbólico como único é esquecer que os elementos que utilizamos para organizar o caos são sempre mitológicos. Transformá-lo em verdade impede o nascimento do pensamento crítico (31). Ouvir o discurso sobre as paixões que amimam a alma humana (seelischer Apparat) dentro de um só modelo é esquecer que o padecer só pode ser totalmente compreendido quando levamos em conta a particularidade da cultura onde ele emerge, isto é, a transculturalidade das formas de subjetivação.

Paulo Roberto Ceccarelli é psicólogo, psicanalista, doutor em psicopatologia fundamental e psicanálise pela Universidade de Paris VII, pós-doutor pela Universidade de Paris VII; membro da Associação Universitária de Pesquisa em Psicopatologia Fundamental; membro da Société de Psychanalyse Freudienne, Paris, França; membro fundador da Rede Internacional de Psicopatologia Transcultural; professor adjunto III no Departamento de Psicologia da PUC-MG.

\section{NOTAS E REFERÊNCIAS BIBLIOGRÁFICAS}

1. Muito deste trabalho se deve às minhas inúmeras idas à Belém, e às interlocuções transdisciplinares que pude estabelecer com profissionais de diferentes áreas. Em todas as idas, sempre tive o carinhoso acolhimento dos colegas e da cidade. A todas e a todos o meu reconhecimento e agradecimento.

2. Ceccarelli P. R.; Lindenmeyer, C. "Traumatisme et sexualité". In: Recherches en psychanalyse. Vol.5. pp.111-118. 2006.

3. Ceccarelli, P. R. "Mitologia e processos identificatórios". In: Tempo psicanalítico. Vol.39. Rio de Janeiro, pp.179-193. Editora: Sociedade de Psicanálise Iracy Doyle (SPID) 2007.

"Mythologie et normalité". In: Bulletin du Centre de Recherche in Psychologie. UBO: Brest. 2008.

4. Godelier, M. Au fondement des sociétés humaines: ce qui nos apprend d'anthropologie. Paris: Albin Michel, 2007. Como Godelier, utilizo a palavra "cultura" para designar "o conjunto de representações e de princípios que organizam conscientemente os diferentes domínios da vida social assim como os valores decorrentes dessas maneiras de agir e de pensar", p.96.2007.

5. Freud, S. (1908). "Moral sexual civilizada e doença nervosa moderna". Edição standard brasileira das Obras Completas.Vol. IX. Rio de Janeiro: Imago, p.192. 1976.

6. Freud, S. op. cit. p.197. 1908.

7. Freud, S. op. cit. p.191. 1908.

8. Godelier, M. op. cit. p.55. 2007.

9. Lemoine, J. "Mythes d'origine, mythes d'identification". In: L'homme. Vol.27, no.101, pp.58-85. 1987. Em muitos mitos, o casal original é incestuoso, composto de um indivíduo, ou de um grupo, e de um parente próximo. A questão central do relato mítico é explicar a passagem da forma de organização incestuosa às sociedades dominadas pela proibição do incesto. Às vezes, essa passagem é marcada pelo dilúvio: a humanidade morre, com exceção de um casal que vai reconstruí-la. A fim de evitar que a nova humanidade fosse igualmente incestuosa, posto que o casal que sobreviveu era incestuoso, o sobrevivente casava-se com uma filha do céu. Na China, o ciclo mítico de Fu Xi et Nü Gua oferece os elementos para a compreensão do contrato social.

10. Freud, S. (1921). "Psicologia de grupo e a análise do ego". Edição standard brasileira das Obras Completas.Vol. XVII. Rio de Janeiro: Imago. p.91. 1976.

11. Ao analisarmos os discursos oriundos de universos diversos, aí incluído o psicanalítico, que salientam consequências catastróficas no tecido social trazidas pelas novas organizações familiares, pelas mudanças culturais relativas aos movimentos das sexualidades e das relações de gênero, não nos passa despercebida a presença dos mitos de origem da cultura ocidental na base dos argumentos apresentados.

12. Gregor, T. Anxious pleasures: the sexual lives of an Amazonian people. Illinois: The University of Chicago Press. 1987. A vida sexual dos Mehináku, um grupo indígena que vive às margens do rio Xingu no Brasil central, é impressionante. Eles falam com entusiasmo e abertamente sobre todos os aspectos do sexo, com um discurso compartilhado por todos. A realidade cotidiana desses indivíduos e a ordem sobrenatural que os regem - seus mitos - são erotizados em um grau que chega a ser surpreendente senão invejável.

13. Devereux, G. Psychothérapie d'un indien des Plaines. Paris: Fayard. p.157. 1998.

14. Róheim, G. Psychanalyse et anthropologie. Paris: Gallimard. 1967.

15. Malinowski, B. (1921). La sexualité et sa répression dans les sociétés primitives. Paris: Payot. 2001.

16. Jecupé, K-W. A terra dos mil povos. São Paulo: Petrópolis. 1998.

17. Lopes da Silva, A. "Mitos e cosmologias indígenas no Brasil: breve introdução". In: Grupioni, L. D. B. Índios no Brasil. SMCSP, pp.75-82. 1992.

18. Lopes da Silva, A. "Mito, razão, história e sociedade: inter-relações nos universos socioculturais indígenas". In: Grupioni, L. D. B. \& Lopes da Silva, A., A temática indígena na escola. MEC/Mari-USP/Unesco, pp.317-335. 1995.

19. Maués, R. H. A ilha encantada: medicina e xamanismo numa comunidade de pescadores. Belém: Igarapé. 1990.

20. Mindlin, B. \& narradores Suruí. Vozes da origem. São Paulo: Ática. 1996.

21. Mindlin, B. Moqueca de maridos. Mitos eróticos. Rio de Janeiro: Rosas dos Tempos. 1998.

22. . O primeiro homem e outros mitos dos índios brasileiros. São Paulo: Cosacnaif. 2001.

23. Mindlin, B. \& narradores indígenas. Mitos indígenas. São Paulo: Ática. 2006.

24. Ribeiro, D. Os índios e a civilização. São Paulo: Companhia das Letras, 1996.

25. Freud, S. (1930 [1929]) "O mal-estar na civilização". Edição standard brasileira das Obras Completas. Vol. XXI. Rio de Janeiro: Imago. 1976.

26. Ferenczi, S. (1932). "Confusão de língua entre os adultos e a criança". In: Obras Completas IV. São Paulo: Martins Fontes. pp.97-108. 1992. 


\section{PSICANÁLISE E LINGUAGEM MÍTICA/ARTIGOS}

27. Weber, M. (1904) L'étique protestante et l'esprit du capitalisme. Paris: Flammarion, pp.259-60. 2002.

28. Regularmente os jornais noticiam escândalos sexuais, tais como as revelações de pedofilia na Igreja Católica, que são, dentro da minha hipótese, uma forma de retorno do reprimido. Quanto mais repressora a sociedade, mais riscos de derrapagens perversas.

29. Ceccarelli, P. R. "A nova ordem repressiva". In: Revista Psicologia, Ciência e Profissão. 2010 (no prelo).

30. Os EEUU talvez sejam o país onde tanto bem e mal, quanto normal e patológico, estejam mais claramente delimitados. Os DSMs serão um reflexo dessa ideologia?

31. Ceccarelli, P. R. "Don Quixote e a transgressão do saber". In: Revista Mal-Estar e Subjetividade (9-3). Fortaleza, pp.879-899. Set. 2009. 